Revista Eletrônica de Ciência Administrativa (RECADM) - ISSN 1677-7387

Faculdade Cenecista de Campo Largo - Coordenação do Curso de Administração

v. 2, n. 2, nov./2003 - http://revistas.facecla.com.br/index.php/recadm/

\title{
IMPACTOS DA TECNOLOGIA DE INFORMAÇÃO NAS ORGANIZAÇÕES
}

LIRA, Waleska Silveira ${ }^{1}$

\section{RESUMO}

O estudo dos Impactos das Tecnologias de Informação, nos últimos tempos, tem crescido de importância tanto na academia como no meio empresarial. A Internet cria um espaço universal para o compartilhamento de informações, servindo como alternativa comercial , mudando todo o sistema de comunicação entre pessoas e empresas, e o próprio comportamento do consumidor, por eliminar os limites territoriais entre empresas e nações. Este estudo procura analisar os impactos causados pela Tecnologia de Informação nas organizações, analisando as mudanças no trabalho, no comportamento das pessoas e organizações. Faz uma reflexão da sociedade da informação como um fenômeno global capaz de transformar atividades sociais, políticas e econômicas se esta sociedade estiver educada para contribuir para a propagação e disseminação da informação para as regiões que sejam atrativas em relação aos negócios e empreendimentos.

Palavras -Chaves - Internet, Sociedade da Informação, Tecnologia de Informação.

\section{INTRODUÇÃO}

O mundo passa por grandes transformações. E as principais causas destas mudanças são a tecnologia, a economia global, a concorrência, os sistemas sociais, a legislação e os próprios consumidores. Teorias que antes geravam bons resultados para a maioria das organizações, não costumam mais ser relevante hoje. A produção em massa e a economia de escala não reduzem mais os custos de transações para empresas, clientes ou consumidor.

Estamos vivenciando a era da informação e o advento de duas forças que serão as bases para se delinear o século XXI são: a Tecnologia Digital e a Globalização. Em ambos os casos necessitam-se de um grande e variado número de informações, pois o acesso a estas informações alterará os estilos e a vida da sociedade e suas expectativas com relação à visão das transformações econômicas, políticas e sociais no mundo todo.

As empresas na era do conhecimento estão utilizando ferramentas digitais para monitorar e aperfeiçoar novos ou antigos processos, como operar seus sistemas de produção, gerar faturas, impostos, automação , visando a melhoria da qualidade de vida dos clientes, empresas e empregados.

A Internet como ferramenta tecnológica cria um espaço universal para o compartilhamento de informações, servindo como alternativa comercial (empresas virtuais), mudando todo o sistema de comunicação entre pessoas e empresas, de gestão estratégica e o próprio comportamento do consumidor, por eliminar os limites territoriais

${ }^{1}$ Professora da Universidade Estadual da Paraíba. Email: Waleska.Silveira@terra.com.br 
Revista Eletrônica de Ciência Administrativa (RECADM) - ISSN 1677-7387

Faculdade Cenecista de Campo Largo - Coordenação do Curso de Administração v. 2, n. 2, nov./2003 - http://revistas.facecla.com.br/index.php/recadm/

entre empresas e nações. Segundo Bill Gates, em seu livro, "A Empresa na Velocidade do Pensamento". Diz que, "Fazer negócios a velocidade do pensamento será a chave para o sucesso no século XXI".

O mundo globalizado $\mathrm{e}$ as tecnologias digitais, trouxeram uma verdadeira revolução nas relações humanas, o comércio eletrônico é uma conseqüência da interação que a rede de computadores nos oferece, possibilitando fazer negócios, obter maior números de informações, numa rapidez e comodidade jamais vista anteriormente.

Com o desenvolvimento dos computadores estamos presenciando uma mudança social e empresarial extremamente enriquecedoras que levarão a diversas tendências para o próximo século. A tecnologia da informação tornou-se o esteio de nossa sociedade, mais rapidamente do que fomos capazes de absorver seus impactos.

É difícil imaginar possíveis impactos, especialmente focalizados aos aspectos empresariais versus sociais de como as empresas e a sociedade estão utilizando estas novas ferramentas informacionais para sobreviverem a esta nova era, para atingir suas metas, satisfazer suas necessidades e as dos clientes seja eles clientes internos e externos.

A sociedade enquanto cliente, está mais exigente e as empresas estão a cada dia mudando sua forma de atrair novos mercados, diante a globalização. Segundo Ralph M. Stair (1998)" a informação correta, se fornecida a pessoa certa, da forma correta e no momento certo, pode melhorar e assegurar a eficiência da empresa".

\subsection{A TECNOLOGIA DE INFORMAÇÃO E SEU IMPACTO NA SOCIEDADE E NAS ORGANIZAÇÕES}

O final do Século $X X$, como o início do século $X X I$, é marcado por impasses e perplexidade. A tônica das reflexões gira em torno da mudança em todos os níveis sociais. A sociedade parece viver, em escala global e mais do que nunca, uma série de profundas e inéditas transformações.

Assim sendo, as transformações operadas durante este século podem ser compreendidas numa visão histórica, comparando-se qualitativamente a sociedade do início com a da última década, de forma sucinta neste livro.

Dentro desta visão, três aspectos fundamentais podem ser ressaltados. Primeiro, o mundo deixou de ser eurocentrico. A Europa, deixa seu papel central do final do século XIX, a população declina, a produção diminui, os centros industriais se mudam para outro lugar. Os Estados Unidos passa a ser a grande economia propulsora da produção e do consumo em massa. O segundo aspecto importante é a mundialização, o processo que 
Revista Eletrônica de Ciência Administrativa (RECADM) - ISSN 1677-7387 Faculdade Cenecista de Campo Largo - Coordenação do Curso de Administração v. 2, n. 2, nov./2003 - http://revistas.facecla.com.br/index.php/recadm/

foi transformado o mundo na unidade básica de operações, suplantando a era da "economias nacionais". A característica fundamental deste final de século XX é a tensão entre a aceleração desse processo e a incapacidade das instituições e dos indivíduos em geral se adaptarem a ele. $O$ terceiro aspecto fundamental é a desintegração dos padrões de relacionamento social. Acontecendo umas ruptura entre passado e presente, dando a dimensão da escala de mudança global, dentro de um âmbito tecnológico, que hoje já não há barreiras territoriais, quando falamos em mundo virtual, Internet, e Comércio Eletrônico.

O conceito de mudança é central ao entendimento da evolução que a sociedade da informação. Este conceito tem sido usado nos diversos meios de comunicação. A informática, o uso da Internet, e o comércio eletrônico. A mudança se tornou uma categoria central no mundo atual, associada com o comportamento das pessoas na sociedade, nas organizações, na economia, no comércio de compra e vendas de produtos e serviços, entre pessoas jurídicas e físicas.

Do ponto de vista da percepção do cidadão comum, este final de século pertence ao movimento. Tanto em extensão, quanto em intensidade, as transformações envolvidas na modernidade são mais profundas do que a maioria das mudanças características dos períodos anteriores. Não só as mudanças estão acontecendo, e mais rápido, mais também nossa percepção das mudanças se torna mais aprofundada pela simultaneidade entre acontecimentos e noticia propiciada pela Tecnologia da Informação, da Internet e principalmente do Comércio Eletrônico.

$\mathrm{Na}$ era da Informação e do conhecimento, o trabalho é profundamente afetado. Uma das transformações mais importantes ligada à revolução industrial se refere a realidade do tempo de trabalho, pela divisão do trabalho, enquanto que na revolução da informação, na era do conhecimento busca-se o homem com visão holística, com visão global, o homem integrado. Onde o homem global está envolvido, não existe trabalho assegurado. $\mathrm{O}$ trabalho aparece com a divisão do trabalho e com a especialização das tarefas. Com a tecnologia da Informação, o homem volta a se envolver- como as sociedades tribais- completamente em seus papeis. Nessa nova organização, o homem se transforma em coletor de informações.

No mundo deste final de século, o homem se volta para a busca do conhecimento e o desenvolvimento dos processos criativos (McLuhan,161).

A tecnologia de informação atinge também a educação, na medida em que passa a ser cada vez mais direcionada para a descoberta, ao invés de apenas no sentido tradicional da instrução. Atualmente as empresas exigem do homem uma visão global, 
Revista Eletrônica de Ciência Administrativa (RECADM) - ISSN 1677-7387

Faculdade Cenecista de Campo Largo - Coordenação do Curso de Administração v. 2, n. 2, nov./2003 - http://revistas.facecla.com.br/index.php/recadm/

munido de uma instrução abrangente e flexível, que tenha criatividade e sobretudo iniciativa.

Portanto partindo a nova era do conhecimento requer do homem um embasamento aprofundado da tecnologia de informação, das ferramentas tecnológicas existentes no mercado, não se concebe atualmente desconhecimento da Internet e o comércio eletrônico, tendo em vista que estas duas ferramentas tecnológicas, é o que tem mais transformado a economia mundial e a sociedade em geral.

A Internet influenciou profundamente $\mathrm{O}$ comportamento da sociedade, possibilitando condições de realizar inúmeras coisas pela rede. A Internet vem conquistando grande espaço na vida dos clientes e dentro de alguns anos tornará uma fonte indispensável na sociedade em geral.

Portanto , se maioria da população tiver acesso à Internet certamente, esta ferramenta tecnológica provocará uma revolução cultural na sociedade.

As tecnologias geram recursos, que geram empregos em outros lugares, ou seja as tecnologias deslocam empregos. As tecnologias trazem produtividade para empresas. A tecnologia pode ter efeito mais predatório em alguns países, porque tudo depende do âmbito em que as tecnologias entram. Portanto se a tecnologia entra numa sociedade onde há crescimento econômico, onde há liberdade de concorrência, educação na população e leis trabalhistas flexíveis, a tecnologia gera emprego.

Outro elemento a ser considerado é a mudança na estrutura ocupacional e no perfil da força do trabalho. Quando a tecnologia elimina posições de trabalho de um determinado perfil profissional, geralmente cria outras posições em maior ou menor quantidade, em outro ponto da indústria, para empregar trabalhadores com outro perfil profissional, de qualquer forma, constata-se que os trabalhadores menos qualificados, ou com qualificações obsoletas, são atingidos pelo desemprego tecnológico (Cattani, p.54). Por outro lado, tendências recentes nas empresas dos processos de trabalho tem incorporado estratégias de redução da divisão técnica do trabalho, da individualização das tarefas e da rígida separação entre concepção e execução, buscando o enriquecimento das tarefas e abrindo espaço para a intervenção dos executivos na modificação dos próprios processos de trabalho com maior autonomia (Cattani, p.66).

Todo este contexto se dá sob o impacto de um mercado globalizado, sob uma reestruturação na produção, com aumento do fluxo de capitais internacionais e aceleração tecnológicas. Há um conflito de visões. De um lado, uma visão em que o homem é substituído pela máquina, com a conseqüente redução do emprego. De outro lado, numa posição em relação as aplicações das novas tecnologias, aponta-se para a 
Revista Eletrônica de Ciência Administrativa (RECADM) - ISSN 1677-7387

Faculdade Cenecista de Campo Largo - Coordenação do Curso de Administração v. 2, n. 2, nov./2003 - http://revistas.facecla.com.br/index.php/recadm/

liberação do ser humano das tarefas menos nobres ( braçais e repetitivas) e sua dedicação as funções mais elevadas ( culturais e de lazer), em virtude do aumento da produtividade e do tempo livre ( Cattani, 172).

No entanto, "é importante observar que, enquanto variável social, a tecnologia pressupõe formas de aplicação diversas a partir de condicionantes que presidem sua introdução, podendo gerar efeitos diferenciado, dependendo de fatores como regime político, onde se inserem as empresas, tradições culturais , desempenho econômico e formas de organização dos trabalhadores".(Cattani, 205)

A tecnologia nos traz conexões eletrônicas entre pessoais no mundo inteiro, noticiais em tempo real, possibilitando a atualizações das informações no mundo, para as empresas esta possibilita maior interatividade com os clientes e fornecedores, atendimento personalizado, menor custo nas operações, rapidez nas informações e uma facilidade maior para otimização das transações, numa nova abordagem de parceria nas cadeias de valor agregados.

Além disso, "o desenvolvimento de novas tecnologias de transporte e telecomunicações estão constantemente redefinindo as fronteiras efetivas entre o local e o nacional e o internacional. Os desenvolvimentos recentes em informática e Telecomunicações estão viabilizando o trabalho a distancia, o que irá afetar a oferta de amo de obra no nível local e internacional, seu perco e sua capacitação". (OECD,11p).

O grande desafio para as noções é ter uma população, cujo processo pedagógico esteja voltado para gerar conhecimento. É necessário ter uma população educada, porque a tecnologia pode destruir um posto de trabalho num campo, e cria em outras áreas, e as pessoas voltadas para o conhecimento, podem ser retreinadas, recicladas, para se adaptarem aos novos postos de trabalhos. Há uma grande revolução do mundo, onde os países que tem educação conseguem absorver e tirar todas as vantagens que a tecnologia oferece e gerar empregos.

Segundo, Drucker (1993:p55-57) a necessidade de se buscar o aumento da produtividade dos trabalhadores de serviços para evitar o perigo de um conflito de classes entre os dois grupos, devido ao reflexo das diferenças de produtividade na remuneração e nos benefícios recebidos pelo trabalhador pode gerar conflito e espera-se que não se acrescente uma terceira classe, a dos desempregados.

Segundo Bridges, "todos as pessoas são trabalhadores contingenciais". Estas pessoas precisam ser consideradas pessoas, cujo valor deve ser demonstrado em cada situação, não as transformando em negócio. 
Revista Eletrônica de Ciência Administrativa (RECADM) - ISSN 1677-7387

Faculdade Cenecista de Campo Largo - Coordenação do Curso de Administração v. 2, n. 2, nov./2003 - http://revistas.facecla.com.br/index.php/recadm/

Numa época em que as empresas já lutam com as mudanças fundamentais geradas pela tecnologia, pela competição mundial e pela transformação no modo de operar, elas não conseguem encontrar pessoal capacitado para liderar estas mudanças. As habilidades exigidas dos profissionais num mundo globalizado e as implicações dessa escassez de talento torna-se ainda mais urgentes. Mas a previsão é de que esse novo mercado de trabalho dificilmente absorverá os excluídos, uma vez que os empregos emergentes exigem um alto grau de qualificação profissional. Dessa forma, o desemprego tende a se concentrar nas camadas menos favorecidas, com baixa instrução escolar e pouca qualificação.

\subsection{A INFORMAÇÃO NA ERA DO CONHECIMENTO}

A Internet como ferramenta tecnológica cria um espaço universal para o compartilhamento de informações, servindo como alternativa comercial (empresas virtuais), mudando todo o sistema de comunicação, o comportamento do consumidor e eliminando os limites territoriais entre nações.

A Internet já é uma realidade mundial, que apesar de nos trazer vantagens, também nos preocupa, em relação à parcela da sociedade que não tem acesso a esta ferramenta, e suas possibilidades no mercado de trabalho.

A era do conhecimento, do capital intelectual, da inteligência competitiva torna o momento atual inédito, sob a ótica das organizações, em que terra, trabalho, matériaprima e capital podem ser considerados recursos finitos, enquanto que o conhecimento visto como capital intelectual é inexaurivel. Nessa perspectiva, todas as áreas da organização precisam ser repensadas. Mattos (1982,p.21), diz que a "moeda está perdendo seu caráter material, transformando-se em mensagem: a moeda eletrônica".

No mundo deste início de século, o homem se volta para a busca de conhecimento e o desenvolvimento dos processos criativos. Nesta visão, a era do conhecimento requer do ser humano um novo perfil, voltado para um ser integrado, com visão multidisciplinar, holística, o olhar global, mais o agir local.

Estes acontecimentos históricos têm transformado o cenário social da vida humana neste início de século. A revolução tecnológica e o desenvolvimento da tecnologia da informação trazem mudanças sociais que levarão a diversas tendências.

O conhecimento torna-se hoje um dos principais fatores de superação de desigualdades, de agregação de valor, criação de emprego qualificado como também de propagação do bem-estar. 
Revista Eletrônica de Ciência Administrativa (RECADM) - ISSN 1677-7387

Faculdade Cenecista de Campo Largo - Coordenação do Curso de Administração v. 2, n. 2, nov./2003 - http://revistas.facecla.com.br/index.php/recadm/

Dentro deste contexto, verifica-se a existência de influências inferidas que refletem no sistema econômico e político dos países. A autonomia dos países depende nitidamente do conhecimento, da educação e do desenvolvimento científico e tecnológico.

Sendo assim, o advento da sociedade da informação está centrada na atuação de novas formas de organização e de produção, em escala mundial, que possa redefinir a inserção dos países menos desenvolvidos na sociedade internacional como também no sistema econômico mundial, tendo como conseqüência para o efetivo funcionamento o comprometimento do Poder Público.

Viver na era da informação é viver constantemente com um volume incalculável de informação que flui a uma velocidade imensa, sem uma percepção clara e questionável por parte da sociedade e que de certa forma assume valores sociais e econômicos importantes, porque não dizer fundamentais.

Como a tecnologia de informação age e quais as suas conseqüências? A tecnologia de informação pode-se dizer, que está inserida dentro de uma imensa malha de meios de comunicação que cobre países inteiros, interliga continentes, chega ao cotidiano das pessoas, às suas casas, ao trabalho, à universidade, através de linhas de fibra ótica, transmissão via satélite, computadores que processam dados transformandoos em informações, controlam e coordenam estes dados, tornando-os acessíveis a diversos meios de comunicação.

Os processos e as funções dominantes na era da informação estão cada vez mais organizados em rede. Segundo Castells (2000,p.497) "redes constituem uma nova morfologia social de nossa sociedade, e a difusão da lógica das redes modifica de forma substancial a operação e os resultados dos processos produtivos e de experiência, poder e cultura".

Portanto, a rede desempenha um papel central na caracterização da sociedade da informação. Rede é um conjunto de nós interligados, onde o nó é o ponto no qual uma curva se intercorta. Podemos exemplificar como um sistema de televisão, equipes para cobertura jornalística e equipamentos móveis gerando, transmitindo e recebendo sinais na rede global.

A rede se caracteriza por ser uma estrutura aberta capaz de se expandir de forma ilimitada, integrando novos nós desde que consigam comunicar-se entre si e dentro da rede. Sua estrutura social é um sistema dinâmico, suscetível de inovação.

É importante ressaltar que a informação é condição essencial para todo cidadão. Esta, por sua vez, não aparece de forma explícita, mas implicitamente fica evidenciada a 
Revista Eletrônica de Ciência Administrativa (RECADM) - ISSN 1677-7387 Faculdade Cenecista de Campo Largo - Coordenação do Curso de Administração v. 2, n. 2, nov./2003 - http://revistas.facecla.com.br/index.php/recadm/

sua necessidade, pois o ato de verificar significa comparar as informações do que ocorreu com as informações do que foi estabelecido. De acordo com Venetianer (2000, p.14)

\begin{abstract}
nós somos de fato uma sociedade de Informação. Agora mais do que nunca o movimentar rápido e por amplas distâncias e vasta quantidade de informações tornou-se uma necessidade imperiosa, pesquisadores de todas as partes do mundo estão descobrindo que suas vidas começam a emaranhar-se com o ambiente das redes computacionais. Acesso imediato ao trabalho de seus colegas, ir a uma biblioteca virtual de milhões de volumes e centenas de milhares de artigos permitem que absorvam um corpo de conhecimento nunca antes imaginado. Grupos de trabalho podem conduzir conferências interativas, derrubando todas as fronteiras e temporais. As possibilidades são infinitas.
\end{abstract}

De acordo com o Programa da Sociedade da Informação (2000,p.3), a convergência da base tecnológica está em três fenômenos inter-relacionados. O primeiro refere-se à convergência da base tecnológica que decorre do fato de se poder representar e processar qualquer tipo de informação, através da tecnologia digital. A segunda referese à dinâmica da indústria, que através da competitividade nas indústrias de informática, tem proporcionado a queda de preços dos equipamentos de informática, possibilitando à população crescente do uso destes equipamentos. E como terceiro e último, o grande crescimento e disseminação da Internet no período de 1991 a 1998. Apesar de ser um serviço restrito a poucos, a velocidade de expansão da Internet, mostra que ela é um fenômeno a ser considerado como instrumento de ampliação do conhecimento, portanto um componente da melhoria da política social para melhoria da educação. A Internet não é miraculosa; por trás dela estão as mesmas pessoas que vivem o dia-a-dia, na rua, na escola, nos escritórios etc...podendo este instrumento ajudar na disseminação do conhecimento e podendo unir virtualmente pessoas interessadas em algum tema em comum.

A sociedade em rede é um fenômeno global capaz de transformar atividades sociais, políticas e econômicas se esta sociedade estiver educada para contribuir para a propagação e disseminação da informação para as regiões que sejam atrativas em relação aos negócios e empreendimentos.

No âmbito social, a sociedade da informação tem um elevado potencial de promover a integração, ao reduzir as distâncias entre pessoas e aumentar o seu nível de informação. Portanto, há uma problemática no que se refere à camada da população que não tem acesso a esta nova tecnologia, e que é questionada por muitos estudiosos no assunto quanto à forma de se evitar ainda mais a disparidade social entre as pessoas, as nações e os blocos de países.

Demo (2000,p.36) ressalta a importância da educação dentro do contexto da sociedade do conhecimento e as políticas sociais, que apontam para a necessidade da 
Revista Eletrônica de Ciência Administrativa (RECADM) - ISSN 1677-7387

Faculdade Cenecista de Campo Largo - Coordenação do Curso de Administração v. 2, n. 2, nov./2003 - http://revistas.facecla.com.br/index.php/recadm/

cidadania emancipatória, mais do que aquelas apenas assistidas e facilmente acomodadas.

"Não se pode, pois, separar educação e conhecimento: este é meio, aquela é fim" (Demo. 2000,p.41).

A globalização é o conjunto de transformações na ordem política e econômica mundial que vem acontecendo nas últimas décadas. O ponto central da mudança é a integração dos mercados numa "aldeia-global", explorada pelas grandes corporações internacionais. Os Estados abandonam gradativamente as barreiras tarifárias para proteger sua produção da concorrência dos produtos estrangeiros e abrem-se ao comércio e ao capital internacional. Esse processo tem sido acompanhado de uma imensa revolução nas tecnologias de informação - telefones, computadores, Internet e o comércio eletrônico.

As fontes de informação também se uniformizam devido ao alcance mundial e a crescente popularização dos canais de televisão por assinatura e a Internet. Isso faz com que os desdobramentos da globalização ultrapassem os limites da economia e comecem a provocar uma certa homogeneização cultural entre os países.

Outro ponto importante desse processo são as mudanças significativas no modo de produção das mercadorias. Auxiliadas pelas facilidades na comunicação e nos transportes, as transnacionais instalam suas fábricas em qualquer lugar do mundo onde existam as melhores vantagens fiscais, mão-de-obra e matérias-primas baratas. Essa tendência leva a uma transferência de empregos dos países ricos que possuem altos salários e inúmeros benefícios, para as nações industriais emergentes. $O$ resultado desse processo é que, atualmente, grande parte dos produtos não tem mais uma nacionalidade definida.

\subsection{CONSIDERAÇÕES FINAIS}

Estamos de fato, diante de uma nova era tecnológica, cuja vantagem é disponibilizar globalmente as informações, expandir micro e pequenas empresas em nível internacional, nacional, independente da sua localização geográfica.

O avanço tecnológico, mais especificamente a Internet e o comércio eletrônico está proporcionado mudanças na economia mundial, gerando um novo padrão de competitividade em que a capacidade de gerar inovações em intervalos de tempo cada vez menor é o que irá fazer o diferencial competitivo para os países e as empresas. 
Revista Eletrônica de Ciência Administrativa (RECADM) - ISSN 1677-7387

Faculdade Cenecista de Campo Largo - Coordenação do Curso de Administração v. 2, n. 2, nov./2003 - http://revistas.facecla.com.br/index.php/recadm/

A utilização dessas tecnologias acelera a racionalidade e flexibilidade na produção de bens e serviços, tornando-os mais eficazes em todo o processo produtivo tanto em termos de recursos natural, capital como também trabalho.

A Internet e o comércio eletrônico propiciam o surgimento de meios para a disseminação da informação e comercialização de produtos e serviços, bem como novas oportunidades de investimento.

Em contrapartida está ameaçando a existência de setores que já não encontram espaço na nova economia. Neste sentido, o mercado passa a exigir das organizações a utilização de novas estratégias de competição, maior descentralização, comunicação bilateral entre empresa/consumidor/fornecedor, com o intuito de estabelecer unidades produtivas em locais onde ofereça maior vantagem, independente de fronteiras geográficas.

Dentro deste panorama, a principal matéria-prima é a informação. A capacidade de gerar, tratar, processar, filtrar e transmitir informação, impõe desta forma um grande desafio tanto para empresas como para os trabalhadores. O desafio de adquirir a competência necessária para transformar informação em um recurso econômico estratégico, um novo paradigma, o conhecimento como produto.

O conhecimento é fator essencial, que por sua vez é adquirido através de um processo de aprendizado mútuo. Requer das organizações treinamento contínuo, como também do governo investimento em políticas sociais do conhecimento, através da uma política educacional adequada á realidade local.

\section{REFERÊNCIAS}

1. ALBERTIN, Luiz Alberto. Comércio eletrônico. Modelo, aspectos e contribuições de sua aplicação. 2.ed. São Paulo: Atlas,2000.

2. ALDRICK, Douglas F. Dominando o mercado digital. Estratégias práticas para a competitividade na nova economia. São Paulo: Makron Books, 2000.

3. AMOR, Daniel. A (r)evolução do e-bussiness. Vivendo e trabalhando em um mundo interconectado. São Paulo: Makron, 2000.

4. BHIMANI, A. Securing the comercial internet communication of the ACM. v. 39, $\mathrm{N}^{\circ}$. 6. p. $29-35$, June 1996.

5. BRIDGES, Willian. Um mundo sem empregos. São Paulo: Makron Books, 1995.

6. CASTELLS, Manuel. A sociedade em rede. A era da informação, economia, sociedade e cultura. 4. ed. São Paulo: Impresso Brasil, 2000. 
Revista Eletrônica de Ciência Administrativa (RECADM) - ISSN 1677-7387

Faculdade Cenecista de Campo Largo - Coordenação do Curso de Administração v. 2, n. 2, nov./2003 - http://revistas.facecla.com.br/index.php/recadm/

7. CATTANI, Antonio. Trabalho e tecnologia: Dicionário Crítico. Rio de Janeiro: Vozes,1997.

8. CHUCK, Martin. O futuro da internet. São Paulo: Makron Books, 2000.

9. DEMO,Pedro. Política social do conhecimento. Petrópolis, RJ: Vozes, 2000.

10. HOBSBAWN, Eric. Era dos extremos: o breve século XX 1914-1991. São Paulo:Companhias das Letras, 1995.

11. JANAL, Daniel. S. Marketing na internet. 2.ed. Rio de Janeiro: ITP, 1996.

12. MATTAR, João. Filosofia e administração. São Paulo: Atlas,1997.

13. MATTOS, João. A sociedade do conhecimento. Brasília: ESA F/UNB, 1982.

14. MCLUHAN, M. Os meios de comunicação como extensões do homem. São Paulo: Cultrix, s/d.

15. MORO,Maria Luísa. Comércio eletrônico: Un Mercado en Expansíon. Madrid: ESIC,2000.

16. NEGROPONTE, N. A Vida Digital. São Paulo: Companhia das Letras, 1995.

17. OECD. Jobs strategy tecnology, productivity and job creation - v.2. Analytical Report. Paris: 1996.

18. KARSAKLIAN, Eliane. Cybermarketing. São Paulo: Atlas,2001.

19. SEYBOLD. B. P. Clientes.com. Como criar uma estratégia empresarial para a internet que proporcione lucros reais.São Paulo: Makron, 2000.

20. TAKAHASHI, T. Sociedade da informação no brasil. Livro Verde. Brasília:2000.

21. VENETIANER, Tom. Como vender seu peixe na internet. Um guia prático do marketing e comércio eletrônico. 3.ed. Rio de Janeiro: Campus,2000.

22. YESIL, Magdalena. Criando a loja virtual. Rio de Janeiro: IBPI. Press, 1999. 